\title{
SENSORLESS VECTOR CONTROL OF INDUCTION MOTORUSING MODEL REFERENCE ADAPTIVE SYSTEM
}

\author{
Sanjaya Kumar Sahu and Archana Gupta \\ Department of Electrical Engineering \\ Bhilai Institute of Technology, Drug, Chhattisgarh, India
}

\begin{abstract}
ABTRACT
The implementation and performance evaluation of sensorless vector control of three-phase induction motor is carried out in this paper which uses Model Reference Adaptive System (MRAS) technique for the estimation of motor speed. Sensorless control is basically a control technique in which speed estimation of motor is done without using speed sensor. Sensorless control increases the robustness, ruggedness of the system and reduces the cost, complexity, electromagnetic interference and maintenance required for the drive. MRAS technique is a widely used technique for speed estimation because of its simple implementation. In order to provide switching control signals to the legs of the IGBT's based two-level inverter; Space Vector Pulse Width Modulation (SVPWM) technique is used in this paper. This technique is based on the rotating space vectors. SVPWM provides better utilization of DC bus voltage and also the harmonic content and the switching losses gets reduced in this technique. The performance of MRAS technique used for speed estimation is evaluated for various values of load torque and speed. The simulation results show the feasibility and robustness of this method for high performance application.
\end{abstract}

Keywords: Field Oriented Control (FOC); Two-level inverter; Space Vector PWM (SVPWM); Model Reference Adaptive System (MRAS); PI control.

Cite this Article: Sanjaya Kumar Sahu and Archana Gupta, Sensorless Vector Control of Induction Motorusing Model Reference Adaptive System, International Journal of Electrical Engineering and Technology, 10(2), 2019, pp. 86-97.

http://iaeme.com/Home/issue/IJEET?Volume $=10 \&$ Issue $=2$

\section{INTRODUCTION}

Three-phase induction motors are widely used in industrial application because of its simple construction, low cost and they are also maintenance free. However, the control of these motor is a challenging problem as they exhibits significant nonlinearities and there are chances that parameters may get effected due to variation in various operating condition. The scalar control method for the control of induction machine is only applicable for steady state condition. So for transient condition this method cannot produce satisfactory performance. Vector control 
provides good performance in transient condition in addition to steady state condition [8]. Vector control or field oriented control allows the control of induction motor similar to that of separately excited DC motor i.e. the field flux and torque can be controlled independently [1][3]. Such control is possible in synchronously rotating reference frame were sinusoidal components appear as DC components at steady state [4]. Because of such control induction motor can replace the traditionally used DC motor for high performance application. Vector control technique requires the calculation of field angle, which requires the calculation of rotor speed.

Speed sensors are used for the estimation of rotor speed. But these sensors are undesirable as they require extra wiring, extra space and electronics which add additional cost to the overall system. Therefore sensorless control of induction motor is widely used in industries. For high performance application different types of sensorless control techniques have been proposed like Slip Calculation, Speed Adaptive Flux Observer, Extended Kalman Filter, MRAS, etc [1], [2]. The closed loop estimation techniques provide better performance compared to open loop estimators. The proposed estimator is a closed loop estimator and widely used because of its simple approach towards the speed estimation [5], [6]. This control method requires the knowledge of stator resistance and stator leakage reactance. Variation in stator resistance may result in poor performance of the drive particularly at low speed, while leakage reactance affects the performance in complete speed range. Thus this model depends upon the machine parameters for its operation [7].

In order to drive three-phase induction motor, two-level inverter is used in this paper. Switching control signals for the legs of inverter is provided by various Pulse Width Modulation (PWM) techniques. Mostly used methods are sinusoidal PWM (SPWM), Hysteresis band current controller and SVPWM. Hysteresis band current controller PWM faces problem related to variable frequency, which varies within the band. This problem can be eliminated by using SVPWM technique [10]. Also SVPWM shows better utilization of DC bus voltage and the switching losses and harmonic content gets reduced when compared with the traditionally used sinusoidal PWM.

\section{INDIRECT VECTOR CONTROL}

As discussed the vector control technique requires the calculation of field angle. Based on how the field angle is measured for the calculation of unit vectors [11], vector control can be classified as direct and indirect vector control. If the calculation of field angle is done by using the terminal voltage or Hall sensor or flux sensing winding then this is called direct vector control. It requires specially designed machine and the fragility of Hall sensor and flux sensing unit detract inherent robustness of induction motor. Indirect vector control calculates the field angle indirectly with the help of machine parameters and without using the variables like voltage and currents. Thus with the use of indirect vector control of induction motor the fixing of flux sensing sensor is not required, as a result the overall cost of the drive gets reduced [1][3]. As a result the dynamic performance in indirect vector control gets improved compared to direct vector control; hence the former is used in most of the industrial applications. The phasor diagram for the vector control of induction motor is shown in Fig. 1. Here the rotor reference axis is rotating at $\omega_{r}$ speed. Synchronously rotating axis is rotating at speed of $\omega$. 


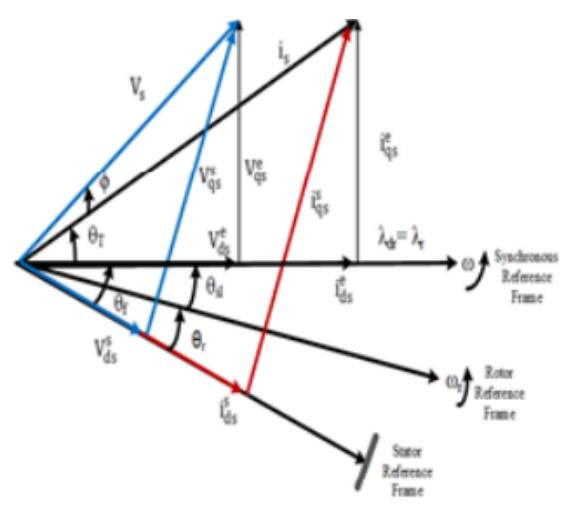

Figure 1 Phasor diagram of vector control of induction motor

From the phasor diagram field angle $\theta_{f}$ is given by

$$
\theta_{f}=\theta_{r}+\theta_{s l}
$$

Where

$$
\begin{gathered}
\theta_{r}=\int \omega_{r} d t \text { and } \theta_{s l}=\int \omega_{s l} d t \\
\therefore \theta_{f}=\int\left(\omega_{r}+\omega_{s l}\right) d t
\end{gathered}
$$

In indirect vector control the estimation of command values (denoted by asterisks) of slip speed $\omega_{s l}^{*}$, direct and quadrature axis stator currents $i_{d s}^{e^{*}}$ and $i_{q s}^{e^{*}}$ in synchronously rotating frame is required for the calculation of field angle and are given by

$$
\begin{array}{r}
\omega_{s l}^{*}=\frac{R_{r}}{L_{r}} \frac{L_{m}}{\lambda_{r}^{*}} i_{q s}^{e^{*}} \\
i_{d s}^{e^{*}}=\frac{1}{L_{m}}\left[\frac{L_{r}}{R_{r}} p \lambda_{r}^{*}+\lambda_{r}^{*}\right] \\
i_{q s}^{e^{*}}=\frac{4}{3 P} \frac{L_{r}}{L_{m}} \frac{T_{e}^{*}}{\lambda_{r}^{*}}
\end{array}
$$

Where $\lambda_{r}^{*}$ is the rotor flux linkage phasor and for constant rotor flux linkage derivative $p \lambda_{r}^{*}=0$, so we have $i_{d s}^{e^{*}}$ as

Here

$$
i_{d s}^{e^{*}}=\frac{\lambda_{r}^{*}}{L_{m}}
$$

$R_{r}, L_{r}, L_{m}$ represents rotor resistance, rotor inductance and magnetizinginductance respectively and $P$ represent the number of poles of motor.

\section{SPACE VECTOR PULSE WIDTH MODULATION}

SVPWM technique is used in this paper to provide switching control signals to the legs of inverter, which can be explained with the help of three-phase bridge inverter as shown in Fig. 2. It is assumed that the switches in each leg are complementary to each other i.e. when $S_{1}$ is turned ON; $S_{4}$ is turned OFF, in a similar way $S_{3}$ and $S_{6}$, as well as $S_{5}$ and $S_{2}$ are also switched. When the upper switches $S_{1}, S_{3}$ and $S_{5}$ are ON (separately or together) this condition is represented by 1 . Similarly when lower switches $S_{4}, S_{6}$ and $S_{2}$ are ON (separately or together) this condition is represented by 0 . 
So the only possible switching states combinations for the 3 leg inverter are $2^{3}=8: 000,001$, $010,011,100,101,110$, and 111 . So 8 possible switching states are possible, out of which two of them are zero switching states $\left(V_{0}, V_{7}\right)$ that produces zero output voltage and six of them are active switching states $\left(V_{1}-V_{6}\right)$ that produces non zero output voltage.

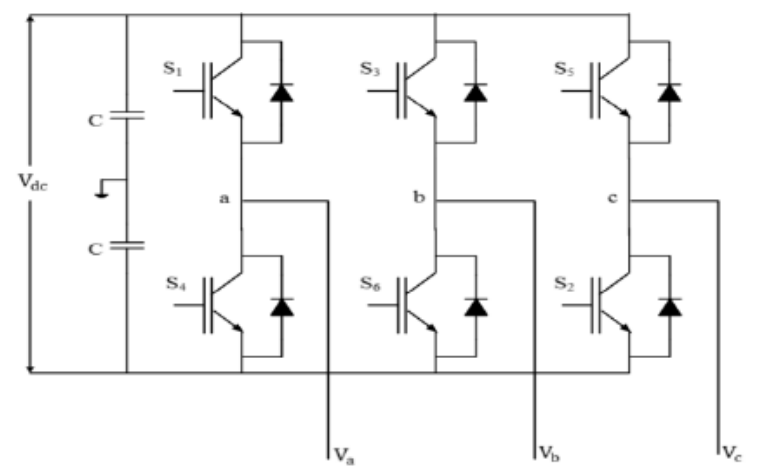

Figure 2 Three-phase bridge inverter

The six active vectors divide the space vector plane into six equal sized sectors of $60^{\circ}$ with equal magnitude which forms an origin centered hexagon [12]-[16]. Two zero space vectors are found at the origin and the six active voltage vector lies along the radii of a hexagon as shown in Fig. 3.

Treat the sinusoidal voltage as a constant amplitude vector rotating at constant frequency. This is known as the average variation of voltage space vector, which is moving along a circulatory trajectory. We need to sample this rotating reference voltage given by $V_{r e f}$ with high sampling frequency which depends upon the size of inverter. Here reference voltage $V_{r e f}$ and sector angle $\alpha$ is given by

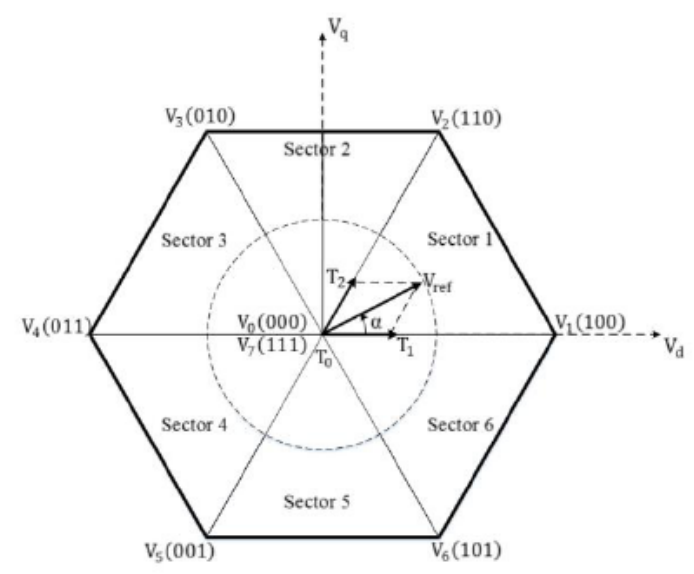

Figure 3 Inverter states and sectors for two-level inverter

$$
\begin{gathered}
V_{\text {ref }}=\sqrt{V_{d}{ }^{2}+V_{q}^{2}} \\
\alpha=\tan ^{-1}\left(\frac{V_{q}}{V_{d}}\right)
\end{gathered}
$$

Where $V_{q}$ and $V_{d}$ are the q-axis and d-axis voltages respectively obtained from the three phase voltages $\left(V_{a n}, V_{b n}, V_{c n}\right)$ by using Clark's transformation and is given by 


$$
\left[\begin{array}{l}
V_{d} \\
V_{q}
\end{array}\right]=\frac{2}{3}\left[\begin{array}{ccc}
1 & -1 / 2 & -1 / 2 \\
0 & \sqrt{3} / 2 & -\sqrt{3} / 2
\end{array}\right]\left[\begin{array}{c}
V_{a n} \\
V_{b n} \\
V_{c n}
\end{array}\right]
$$

The position of $V_{r e f}$ from the start of the sector determines the voltage vector associated with the sector. Voltage vector corresponding to position of $V_{\text {ref }}$ provides the switching signal for the IGBT's of the two-level inverter.

\section{SPEED ESTIMATION USING MRAS}

Model reference adaptive system uses two model known as reference and adaptive model. Both the models are used for the calculation of flux. The fluxes obtained from both the models are compared to produce an error signal which is responsible for the estimation of motor speed [5][7]. If the fluxes obtained from both the models is same i.e.

$$
\lambda_{d r}^{s}=\hat{\lambda}_{d r}^{s} \text { and } \lambda_{q r}^{s}=\hat{\lambda}_{q r}^{s}
$$

Then the accurate value of speed is estimated. Here, $\lambda_{d r}^{S}$ and $\lambda_{q r}^{S}$ are the outputs obtained from the reference model and $\hat{\lambda}_{d r}^{s}$ and $\hat{\lambda}_{q r}^{s}$ are the outputs obtained from adaptive mode in stationary reference frame. The dynamic equation of induction motor in stationary reference frame is used for obtaining the outputs from both the model. Fig. 4 shows the dynamic equivalent circuit diagram of induction motor in stationary reference frame [1].
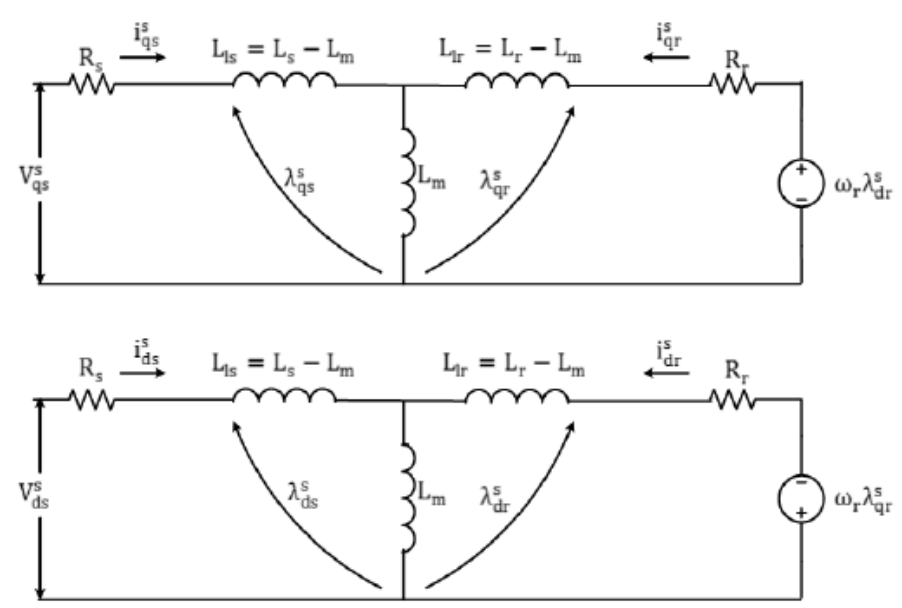

Figure 4 Dynamic equivalent circuit of induction motor instationary reference frame

The stator voltage obtained from the dynamic equivalent circuit diagram as

$$
V_{d s}^{S}=R_{s} i_{d s}^{s}+L_{l s} \frac{d}{d t}\left(i_{d s}^{s}\right)+\frac{d}{d t}\left(\lambda_{d m}^{s}\right)
$$

Where,

$$
\begin{aligned}
& \lambda_{d m}^{s}=L_{m}\left(i_{d s}^{s}+i_{d r}^{s}\right) \\
& \lambda_{q m}^{s}=L_{m}\left(i_{q s}^{s}+i_{q r}^{s}\right) \\
& \lambda_{d r}^{s}=L_{m} i_{d s}^{s}+L_{r} i_{d r}^{s} \\
& \lambda_{q r}^{s}=L_{m} i_{q s}^{s}+L_{r} i_{q r}^{s}
\end{aligned}
$$

Here $V_{d s}^{S}$ and $i_{d s}^{S}$ represents d-axis stator voltage and current when referred stationary reference frame and $\lambda_{d m}^{S}$ represents d-axis magnetizing flux linkage when referred to stationary reference frame. 
Substituting the value from equation (13) in equation (12) and further solving it we get

$$
\begin{gathered}
V_{d s}^{s}=R_{s} i_{d s}^{s}+L_{l s} \frac{d}{d t}\left(i_{d s}^{s}\right)+\frac{d}{d t}\left[\left(\lambda_{d r}^{s}+L_{l r} i_{d s}^{s}\right) \frac{L_{m}}{L_{r}}\right] \\
V_{d s}^{s}=\frac{L_{m}}{L_{r}} \frac{d}{d t} \lambda_{d r}^{s}+R_{s} i_{d s}^{s}+L_{l s} i_{d s}^{s} S+L_{l r} \frac{L_{m}}{L_{r}} i_{d s}^{s} S
\end{gathered}
$$

Substituting the value of $L_{l s}$ and $L_{l r}$ from dynamic equivalent circuit in above equation we get

$$
\begin{gathered}
\therefore V_{d s}^{S}=\frac{L_{m}}{L_{r}} \frac{d}{d t}\left(\lambda_{d r}^{S}\right)+\left(R_{s}+\sigma L_{s} S\right) i_{d s}^{S} \\
\text { Where, } \sigma=1-\frac{L_{m}^{2}}{L_{r} L_{s}} \\
\frac{d}{d t}\left(\lambda_{d r}^{S}\right)=\frac{L_{r}}{L_{m}} V_{d s}^{S}-\frac{L_{r}}{L_{m}}\left(R_{s}+\sigma L_{s} S\right) i_{d s}^{S}
\end{gathered}
$$

Similarly we can have,

$$
\frac{d}{d t}\left(\lambda_{q r}^{s}\right)=\frac{L_{r}}{L_{m}} V_{q s}^{s}-\frac{L_{r}}{L_{m}}\left(R_{s}+\sigma L_{s} S\right) i_{q s}^{s}
$$

From equation (18) and (19) we get

$$
\left[\begin{array}{l}
\dot{\lambda}_{d r}^{s} \\
\dot{\lambda} s
\end{array}\right]=\left[\begin{array}{l}
L_{q r} \\
L_{m}
\end{array}\left[\begin{array}{l}
V_{d s}^{s} \\
V_{q s}^{s}
\end{array}\right]-\left[\begin{array}{cc}
\left(R_{s}+\sigma L_{s} S\right) & 0 \\
0 & \left(R_{s}+\sigma L_{s} S\right)
\end{array}\right]\left[\begin{array}{l}
i_{d s}^{S} \\
i_{q S}^{s}
\end{array}\right]\right.
$$

The above equation represents the output of reference model. The input to this model is the stator voltage and current. Similarly adaptive model uses the dynamic equivalent circuit of induction motor for obtaining the flux linkage. From the dynamic equivalent circuit as shown in Fig. 4 we have

$$
\frac{d}{d t}\left(\lambda_{d r}^{S}\right)+R_{r} i_{d r}^{S}+\omega_{r} \lambda_{q r}^{S}=0
$$

Adding $\left(L_{m} \frac{R_{r}}{L_{r}}\right) i_{d s}^{s}$ to both side of above equation and on solving we get

$$
\frac{d}{d t}\left(\lambda_{d r}^{s}\right)=\frac{L_{m}}{T_{r}} i_{d s}^{s}-\omega_{r} \lambda_{q r}^{s}-\frac{1}{T_{r}} \lambda_{d r}^{s}
$$

$T_{r}$ is the rotor time constant and is given by

Similarly we can have

$$
T_{r}=\frac{L_{r}}{R_{r}}
$$

$$
\frac{d}{d t}\left(\lambda_{q r}^{s}\right)=\frac{L_{m}}{T_{r}} i_{q s}^{s}+\omega_{r} \lambda_{d r}^{s}-\frac{1}{T_{r}} \lambda_{q r}^{s}
$$

From equation (22) and (24) we get

$$
\left[\begin{array}{l}
\dot{\lambda}_{d r}^{s} \\
\dot{\lambda}_{q r}^{s}
\end{array}\right]=\left[\begin{array}{cc}
-\frac{1}{T_{r}} & -\omega_{r} \\
\omega_{r} & -\frac{1}{T_{r}}
\end{array}\right]\left[\begin{array}{l}
\lambda_{d r}^{s} \\
\lambda_{q r}^{s}
\end{array}\right]+\frac{L_{m}}{T_{r}}\left[\begin{array}{l}
i_{d s}^{s} \\
i_{q s}^{s}
\end{array}\right]
$$


The equation (25) corresponds to the adaptive model which contains the rotor speed. This rotor speed i.e. actually the estimated speed, adapts the actual motor speed.

Fig. 5 shows the block diagram of sensorless vector control using model reference adaptive system. Here the difference between the state variables of the reference and the adaptive model are manipulated into speed tuning signal $\xi$. This signal is the input to a PI controller, whose output is the estimated rotor speed [2].

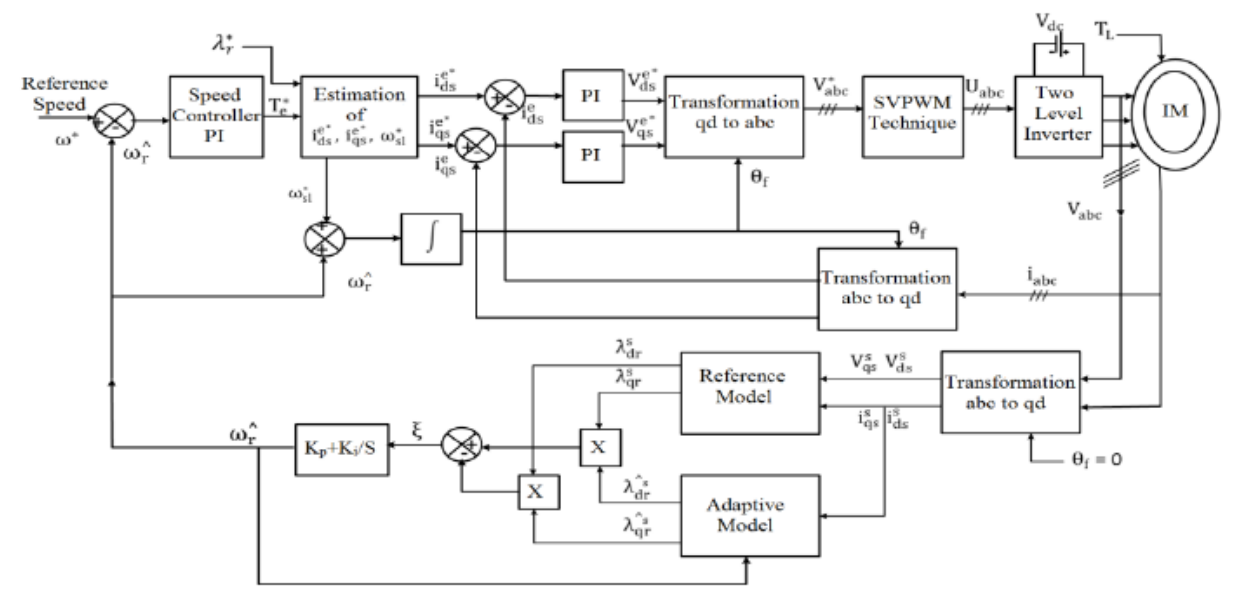

Figure 5 Block diagram of sensorless vector control of induction motor using MRAS

In practice, the reference model is difficult to implement because of the presence of pure integration required for the voltage signal. Due to the presence of pure integration reference model have initial value problem and drift problem [1], [2]. However in practical implementation, this problem can be eliminated by using a low pass filter [9], with transfer function $1 /(S+1 / T)$

As in practical system, the reference model contains $1 / S$ (pure integration) thus the model is followed by high pass filter with transfer function $S /(S+1 / T)$. As the output of the reference model gives modified value of rotor flux linkage because of the high pass filter, the adaptive model should also be adjusted according to that.

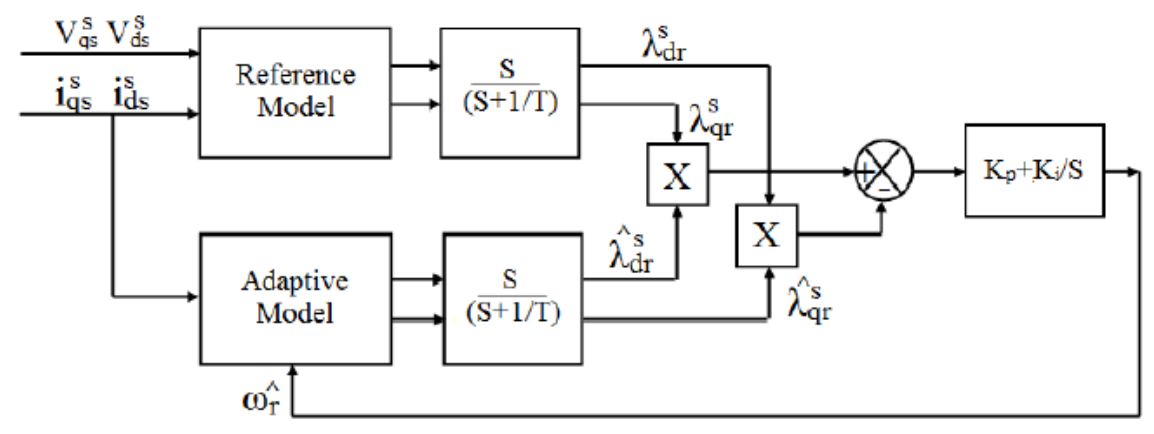

Figure 6 Block diagram for practical implementation of MRAS

Therefore a high pass filter with similar transfer function is placed in front of the original adaptive model as shown in Fig. 6. In practical application the cut-off frequency of high pass filter is few Hertz. Below the cut-off frequency the rotor speed estimation is inaccurate. Also accurate value of stator resistance is required for better performance of the estimator.

However, when MRAS method is used in vector controlled induction motor drive, speed reversal through zero is possible for a fast transient process but the speed control is lost if the drive is operated at zero frequency for more time, due to incorrect flux linkage estimation. 


\section{SIMULATION RESULTS AND DISCUSSION}

Simulation model for the vector control of induction motor drive is developed and simulated using MATLAB/ SIMULINK software. The motor parameters are shown in Table 1. The simulation model uses PI controller, used as speed controller, it is also used for the generation of command voltage from the error signal produced by comparing the actual machine current and estimated value of current. In addition to these controllers, PI controller is also responsible for the estimated of speed obtained by balancing the fluxes of reference model and the adaptive model.

TABLE 1 Parameters of Induction Motor

\begin{tabular}{|c|c|c|}
\hline Parameters & Symbol & Values \\
\hline Rated Power & $\mathrm{P}_{\text {rated }}$ & $2 \mathrm{Hp}$ \\
\hline Rated Voltage & $\mathrm{V}$ & $400 \mathrm{Volt}$ \\
\hline Rated Frequency & $\mathrm{f}$ & $50 \mathrm{~Hz}$ \\
\hline Number of Poles & $\mathrm{P}$ & 4 \\
\hline Stator Resistance & $\mathrm{R}_{\mathrm{s}}$ & $4.850 \Omega$ \\
\hline Rotor Resistance & $\mathrm{R}_{\mathrm{r}}$ & $3.805 \Omega$ \\
\hline Stator Inductance & $\mathrm{L}_{\mathrm{s}}$ & $0.274 \mathrm{H}$ \\
\hline Rotor Inductance & $\mathrm{L}_{\mathrm{r}}$ & $0.274 \mathrm{H}$ \\
\hline $\begin{array}{c}\text { Mutual } \\
\text { Inductance }\end{array}$ & $\mathrm{L}_{\mathrm{m}}$ & $0.258 \mathrm{H}$ \\
\hline $\begin{array}{c}\text { Moment of } \\
\text { Inertia }\end{array}$ & $\mathrm{J}$ & $0.03 \mathrm{~kg} . \mathrm{m}^{2}$ \\
\hline
\end{tabular}

Fig. 7 shows the performance of motor at no load and for a constant speed of 1400rpm. The motor achieves the reference speed of $1400 \mathrm{rpm}$ at $0.5 \mathrm{sec}$ with some overshoot i.e. due to presence of the PI controller used. The estimated speed is almost similar to motor speed. Fig. 8 shows the stator current which is the output current of the inverter. The currents are sinusoidal with almost negligible ripple content
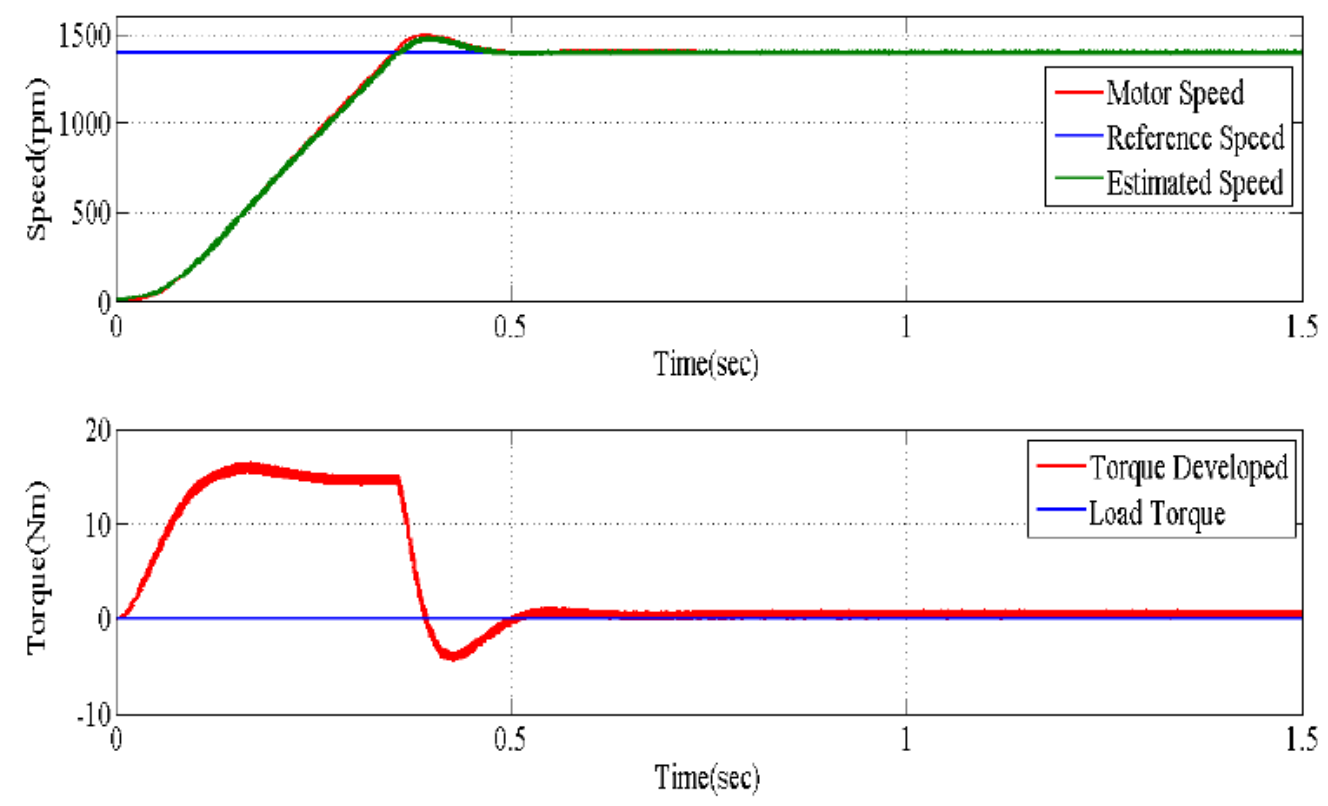

Figure 7 Performance of motor at no load and constant speed 

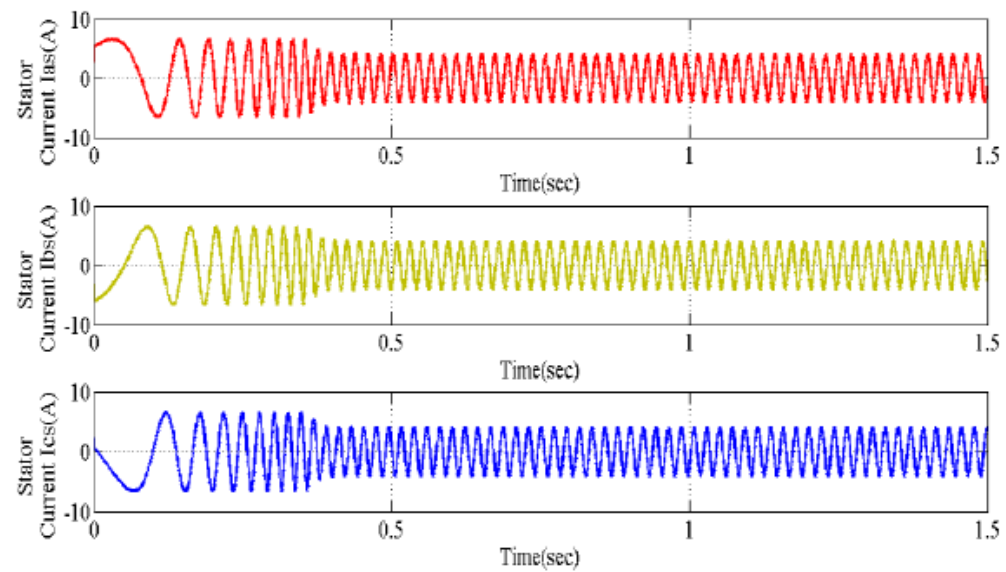

Figure 8 Stator current (output current of inverter)
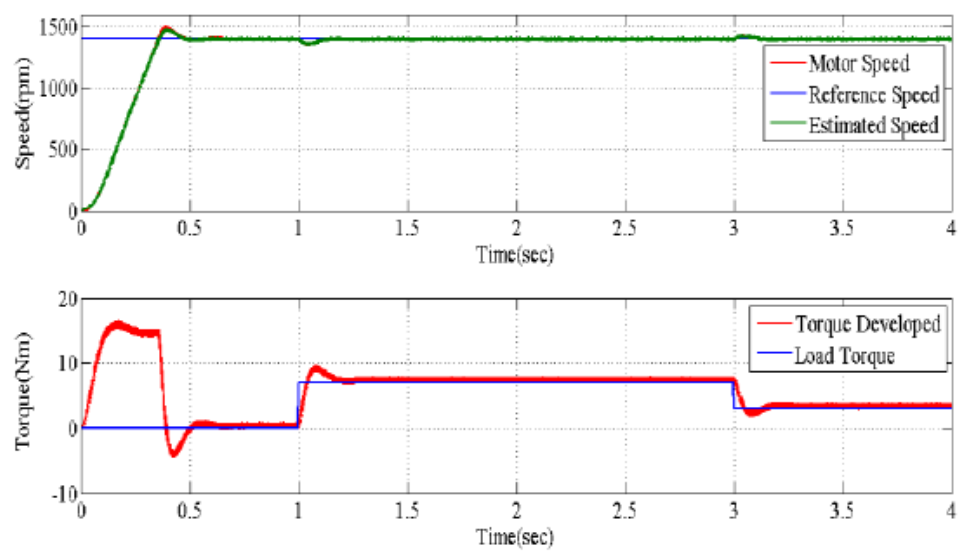

Figure 9 Performance of motor at constant speed and variableload torque

Fig. 9 depicts the performance of motor for a constant speed of $1400 \mathrm{rpm}$ and variable load torque. The load torque is varied from no load to $7 \mathrm{Nm}$ at $\mathrm{t}=1 \mathrm{sec}$ and from $7 \mathrm{Nm}$ to $3 \mathrm{Nm}$ at $\mathrm{t}=3 \mathrm{sec}$.

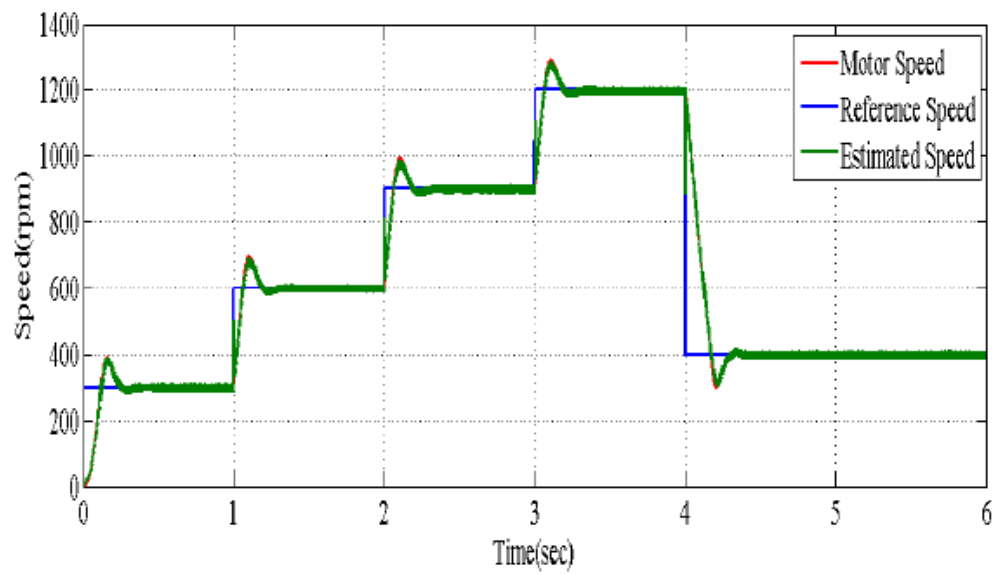

Figure 10 Performance of motor for step speed variation

Fig. 10 shows the performance of motor for variable step speed variation and for a constant no load torque. It can be observed that the motor speed and the estimated speed are almost the same and motor speed tracks the reference speed with a very small variation. Fig. 11 shows the performance of motor for variable speed and variable load torque. 

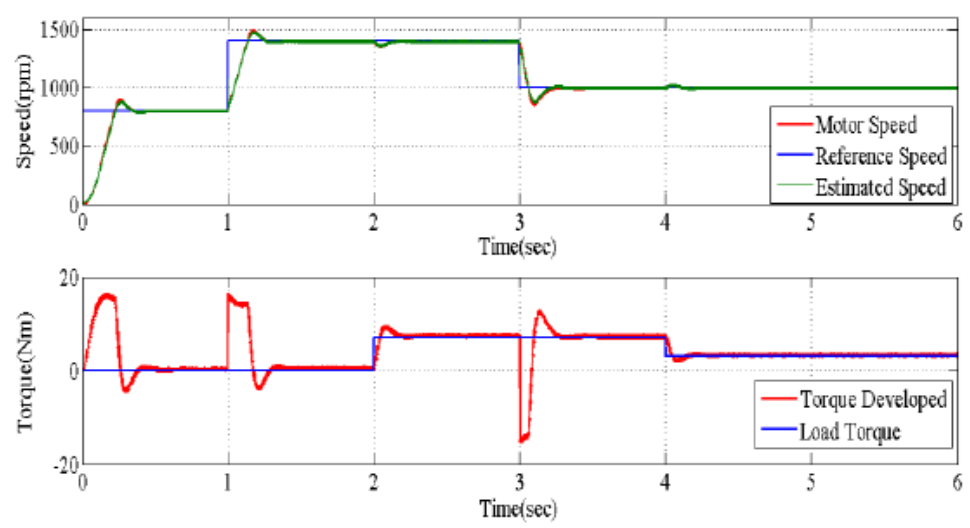

Figure 11 Performance of motor for variable speed and variableload torque

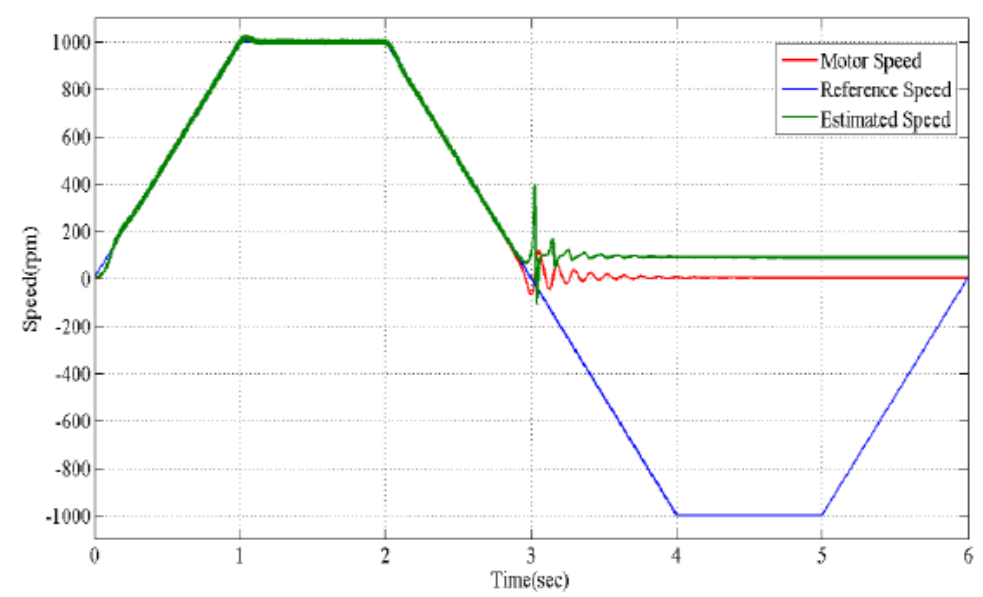

Figure 12 Trapezoidal speed tracking performed at no load

As discussed earlier the speed reversal through zero is not possible if the drive operates at zero frequency for more time. Hence in this case when using MRAS, it is difficult for the motor to track the trapezoidal speed tracking due to incorrect flux linkage estimation as shown in Fig. 12. However the estimated speed can track the negative reference speed, but system faces problem in changeover of speed from negative speed to positive speed or vice versa due to incorrect flux estimation.

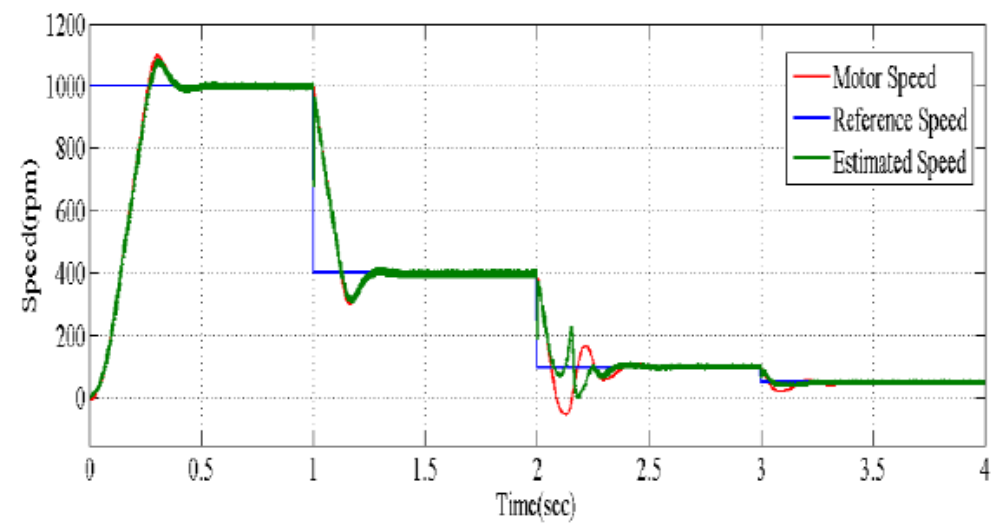

Figure 13 Performance of motor at low speed of operation

Fig. 13 depicts the performance of motor at low speed of operation. At low speed when speed is varied from $400 \mathrm{rpm}$ to $100 \mathrm{rpm}$, the system finds difficulty in tracking the reference 
speed at the transient but tracks the speed efficiently at steady state. The rotor speed estimation becomes inaccurate below the cutoff frequency. This is one of the drawbacks of speed estimation by model reference adaptive system.

\section{CONCLUSION}

The model reference adaptive system method used in this paper for estimation of speed of induction motor tracks the reference speed efficiently in all the condition except the trapezoidal speed tracking. This was due to incorrect flux linkage estimation, as the drive operated at zero frequency for more time. Also at low speed the system faces difficulty in tracking the reference speed at the transients but tracks the reference speed efficiently at steady state. These are the limitations associated with the MRAS technique used in this work. The simulation results testify that rotor speed can be estimated efficiently using MRAS technique and thus can replace the speed sensor but with certain limitation, particularly at low speed and at zero frequency.

\section{REFERENCES}

[1] B.K. Bose, Modern power electronics and AC drives, Pearson India Education Service Pvt. Ltd, New Delhi, 2016

[2] P. Vas, Sensorless vector and direct torque control, Oxford University Press, Newyork, 1998

[3] R. Krishnan, Electrical motor drives, modelling, analysis, and control, PHI Learning Pvt. Ltd, New Delhi, 2014

[4] R.J. Lee, P. Pillay, R.G. Harley, “ D, Q reference frames for the simulation of induction motors," Electrical Power System Research, Vol. 8, pp.15-26, April 1984

[5] G.K. Nisha, Z.V. Lakaparampil, S. Ushakumari, "Sensorless field oriented control of SVM inverter Fed induction machine in field weakening region using sliding mode observer," Proceedings of the World Congress on Engineering, Vol. 2, pp.33-38, July 2013.

[6] G.K. Nisha, Z.V. Lakaparampil, S. Ushakumari, "Four- quadrant operation of sensorless FOC induction machine in field weakening region using MRAS-sliding mode observer," IEEE International Conference on Control Communication and Computing, pp.33-38, 2013

[7] D.D. Pinheiro, C.M.O. Stein, J.P. Costa, R. Cardoso, E.G. Carati, "Comparison of sensorless techniques based on model reference adaptive system for induction motor drives," 13th IEEE Power Electronics Conference and 1st Southern Power Electronics Conference, pp.1-6, 2015.

[8] J.A. Satisteban, R.M. Stephen, "Vector control methods for induction machines: An Overview," IEEE Transactions on Education, Vol.44, No.2, pp.170-175, May 2001

[9] C. Schaunder, "Adaptive speed identification for vector control of induction motors without rotational transducers," Conference Record of IEEE Industrial Application Society Annual Meeting, pp.493-499, 1989

[10] A.P. Fizatul, M. Sulaiman, Z. Ibrahim, "Comparison performance of induction motor using SVPWM and hysteresis current controller," Journal of Theoretical and Applied Information Technology, Vol. 30, No. 01, pp.10-17, August 2011

[11] K. Hemavathy, N. Pappa, S. Kumar, "Comparison of indirect vector control and direct torque control applied to induction motor drive," IEEE International Conference on Advanced Communication Control and Computing Technologies (ICACCCT), pp.192-197, 2014.

[12] H.W.V.D. Broeck, H.C. Skudelny, G.V. Stanke , "Analysis and realization of a pulse width modulator based on voltage - Space Vectors," IEEE Transactions on Industry Applications, Vol. 24, No. 01, pp.142-150, January 1988. 


\section{Sanjaya Kumar Sahu and Archana Gupta}

[13] P.S. Varma, G. Narayanan, "Space vector PWM as a modified form of sine-triangle PWM for simple analog or digital implementation," IETE Journal of Research, Vol.52, No.6, pp.435-449, November-December 2006.

[14] M. Gaballah, M. El-Bardini, S. Sharaf, M. Mabrouk, "Implementation of space vectorPWM for driving two level voltage source inverters," Journal of Engineering Sciences, Assiut University, Vol.39, No.4, pp.871-884, July 2011.

[15] M.M. Gaballah, "Design and implementation of space vector PWM inverter based on a low cost microcontroller," Springerlink.com, Vol.38, pp. 3059-3070, December 2012.

[16] Z.B. Ibrahim, M.L. Hossain, I.B. Bugis, N.M.N. Mahadi, A. Shukri, A. Hasim, "Simulation investigation of SPWM, THIPWM and SVPWM techniques for three phase voltage source inverter," International Journal of Power Electronics and Drive System, Vol.4, No.02, pp.223-232, June 2014. 